\title{
Understanding the Mediating Effect of Word of Mouth on Green Products Purchase Intention
}

\author{
Mayank Pant, Anu Sayal, Mohammad Tariq Intezar, V K Tangri
}

\begin{abstract}
Green products are the future and to ensure that we are living a safe and comfortable life without pollution we need to ensure that green marketing helps in making masses aware about the importance of green products so that there is harmony green products are safe and Sensitive to Ecological Concerns or presumed as 'Safe' to the Environment. Such products are also considered to be 'Biodegradable'. In numerous researches conducted in India it was seen that there is knowledge about green products are there but since India is a price conscious market the acceptance level has still not reached the level it should. Green knowledge has been quite prominent and with positive word of mouth, since with the advent of green revolution this paper attempts to see the mediating effect of Mediation, Green purchase Intension, Green revolution. Though, most people understand 'Green Products', but whether 'Word of Mouth can induce them to use these products is the main theme of this research. It is found that such products are required to be reasonably priced so that these affordable by middle classes also. The study found that the 'Word of Mouth' is associated in a positive manner with intention to buy green products.
\end{abstract}

Index Terms: Word of mouth, Mediation, Green purchase Intension, Green revolution.

\section{INTRODUCTION}

After going through the Literature Review available on the subject, it is evident that though many other areas information about Green Marketing is available and a lot of related research has been conducted by other researchers, but there is surely a gap in the research regarding the mediation of 'Word of Mouth' on intention to buy Green products. It is a significant area, because though the people are well informed about Green products and their impact on environment protection, but unconsciously they neglect the purchase. However, when a third person recommends it, they are motivated to buy it. But, no researcher seems to have done it, hence this study was conducted.

\section{LITERATURE REVIEW:}

Cherian and Jacob in the year 2012 conducted a survey on the purchase pattern of people on eco friendly products that are environment safe. They studied various aspects of green marketing. Through their study they concluded that there is a requirement of a transition in the consumer behavior and attitude towards those products that are environment friendly.

Revised Manuscript Received on October 5, 2019.

Mr.Mayank Pant, Research Scholar in Uttaranchal University, pant_m@yahoo.com

Ms Anu Sayal, Ms. Anu Sayal, Assistant Professor in Mathematics in Uttaranchal Institute of Management, Uttaranchal University, Dehradun

Dr Mohammad Tariq Intezar, Associate Professor in University of Petroleum and Energy Studies Dehradun

Mr V K Tangri Assistant Professor in Uttarancal University in Uttaranchal Institute of Management
They recommended a need of exploration of all the factors due to which the consumers are encouraged to cooperate with green marketing.

In 2006 D'souza, Taghian and Lamb did a research on the impact of surrounding knowledge to consumers on the basis of labels. This study was conducted through the questionnaires administered through telephonic conversation. These were later analysed using correlation and the descriptive measures.

Bhatia and Jain in the year 2013 provided a complete review based on the issues related to environment, green products, green practices related to consumers and the level of awareness among the consumers. For studying all such issues the preferences as well as the perceptions of the consumers were analyzed with the help of structured questionnaires.

Chen and Chai in 2010 targeted their study on demographics with special reference to gender. The study found that males are more inclined to buy green products then their counterparts and this led to more purchases. Attitude was also studies and the role of WOM was also analysed.

Yazdanifard and Mercy in 2011 provided a complete review of literature for analyzing the impact due to the combined efforts to overcome the impact of green marketing which has become quite evident with the bringing of knowledge that can be easily understood with that renders protection to all.

Sheikh, Mirza, Aftab and Asghar in 2014 conducted a study for investigating how gender react to purchases of green products and the role of knowledge in analysis the behaviour and attitude of green marketing in the presence of WOM.

Diabat and Govindan in 2011 proposed the requirement of establishing an eco-friendly supply chain, which is a a big challenge as well as an issue of concern in the present century.

Considering the present scenario we observe that numerous challenges are being faced for implementation as well as marketing and popularizing green products. Govindan et al. in 2014, Jayant and Azhar in 2014 elicited the fact that the unavailability of bank loans for financing the green products is a hindrance in popularising the green supply chain. Also switching to the green system from the existing system is a costly process and this was studied by Mudgal et al. in 2010, Carter and Dresner in 2001, Bowen et al. in 2001 revealed the fact that there is a lack of proper training for the implementation of the green products.

Carter and Dresner in 2001 and Bowen et al. in 2001 concluded that is a lack of awareness in adopting the green products which is the main cause of low popularity of these products. 
Shen and Tam in 2002 revealed the fact that there is scarcity of knowledge related to the environmental issues and this is the root cause as to why the people are not ready to switch to the green products. Ravi and Shankar in 2005, Mudgal et al. in 2010, Revell and Rutherfoord in 2003 conducted a study according to which it was concluded that awareness of the environmental issues is lacking among the vendors and suppliers and this is a hindrance in making increasing the popularity of the green products as well as the green supply chain.

Hosseini in 2007 proposed that there should be adoption and implementation of the highly advanced technologies for improving the management performance of the environment. The organizations which are resistant to the adoption of the advanced technologies actually experience difficulty in implementation of the green supply chain management.

\section{RESEARCH METHODOLOGY}

The current research aims to understand the consequences of word of mouth on green purchase intension, we undertook structural equation modeling technique to analysis this effect and we did an exploratory factor analysis using varimax rotation. We had 17 questions and out of those 9 were retained and the rest had to be omitted. The reason for omission was that while conducting the exploratory factor analysis we suppressed small coefficients less than 0.70 . Since we wanted a low CIM/df value and it could be possible only when we have factor loadings more than 0.70 . The proposed model in figure 1 is the model we wanted to test

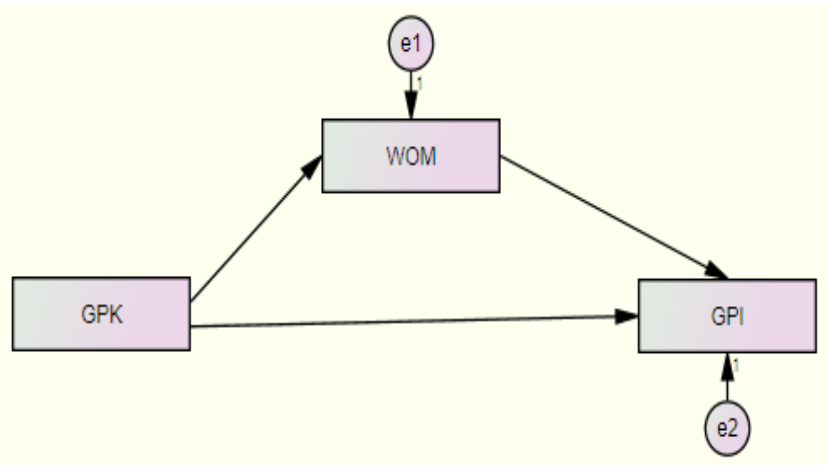

Figure 1 Model to be tested

The research was to analyze the mediating effect of WOM word of mouth on eco friendly products, as evident from the proposed model we had three hypothesis.

H1:->GPK has no effect on GPI

H2:-> GPK has no effect on WOM

H3:->WOM has no effect on GPI

Table 1 shows the scales used in the research which has details of the questions asked from respondents, with the construct name, the items in each constructs and the questions that had factor loading above 0.70 .

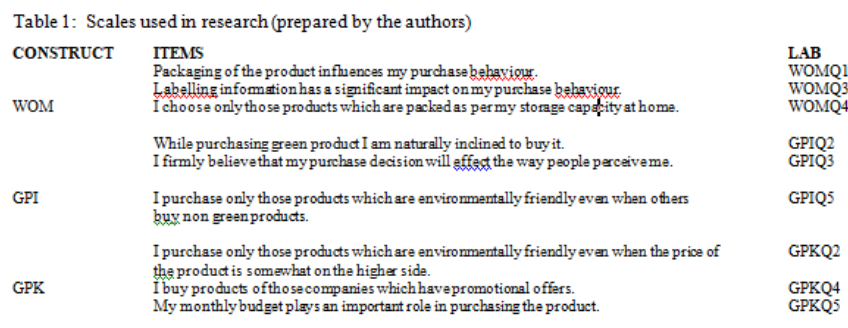

The entire model was later tested for its reliability and validity, and the reliability was accesses using Cronbach's Alpha which tests the internal consistency to see if a construct is complete in itself by checking for alpha value above 0.70 table 2 and since all our constructs were above 0.70 we can firmly say that reliability is not an issue in our study. The next check was validity and that was done using AVE and Composite Reliability, the AVE of a construct must be above 0.50 and Composite Reliability above 0.70 and AVE must be less than Composite Reliability, as shown below we met this criteria also, this indicated that our discriminant validity holds true. Table 3 is another check for discriminant validity we did this for being absolutely sure for the fact that our construct were different in explaining their intended parameter as it serves as a second check to make our model robust.

Table 2: Details of Convergent and Discriminate Validity

\begin{tabular}{|c|c|c|c|c|c|}
\hline LatentVariable & Items & Value & AVE & CR & Crophach's a \\
\hline \multirow{3}{*}{ WOM } & WOMQ1 & 0.792 & \multirow{3}{*}{0.6134} & \multirow{3}{*}{0.9049} & \multirow{3}{*}{0.8744} \\
\hline & WOMQ3 & 0.812 & & & \\
\hline & WOMQ4 & 0.757 & & & \\
\hline \multirow{3}{*}{ GPI } & GPIQ2 & 0.742 & \multirow{3}{*}{0.5401} & \multirow{3}{*}{0.8234} & \multirow{3}{*}{0.7153} \\
\hline & GPIQ3 & 0.628 & & & \\
\hline & GPIQ5 & 0.798 & & & \\
\hline \multirow{3}{*}{ GPK } & GPRQ2 & 0.75 & \multirow{3}{*}{0.597} & \multirow{3}{*}{0.8162} & \multirow{3}{*}{0.6698} \\
\hline & GPRQ4 & 0.804 & & & \\
\hline & GPRQ5 & 0.762 & & & \\
\hline
\end{tabular}

The next check for validity is convergent validity for which we use quality criteria table 4 showing the communality and redundancy the values were positive and the reference value was large, indicating that all items converge to their respective factor.

Table 3: Discriminate validity

\begin{tabular}{|l|r|r|l|}
\hline $\begin{array}{c}\text { AVE Sq } \\
\text { root } \\
\text { compariso } \\
\mathrm{n}\end{array}$ & WOM & GPI & GPK \\
\hline WOM & $\mathbf{0 . 7 3 4 9 1 5}$ & & \\
\hline GPI & 0.6921 & $\mathbf{0 . 7 5 5 9 7 6}$ & \\
\hline GPK & 0.5797 & 0.6944 & $\mathbf{0 . 7 8 4 4 7 4}$ \\
\hline
\end{tabular}

This table 3 is indicating the discriminate validity which must be more than the inter item correlation between other constructs, we basically look for the value in bold which is square root of AVE to be above the values below and off diagonal to it. 
This is an indication that one construct is different from the other and there is no possibility that one construct is explaining the same variance as the other.

Table $4: R^{2}$, Communalities with Redundancy

\begin{tabular}{llcl} 
& $\mathrm{R}^{2}$ & Communality & Redundancy \\
\hline WOM & 0.000 & 0.7422 & 0.0000 \\
GPI & 0.536 & 0.7834 & 0.1605 \\
GPK & 0.000 & 0.7287 & 0.0000 \\
\hline Reference & 0.02 as small, & Positive & Positive \\
Value & 0.13 as medium, and & & \\
& 0.26 as large. & &
\end{tabular}

Since our model is a mediation model, in which we wanted to know if word of mouth mediates knowledge which ultimately leads to purchase. But before mediation to occur we need to have a significant relation between IV and DV without mediation, in simple words we say that before we analyze that word of mouth mediates green product knowledge which leads to green purchase intension we need to check for a statistically significant effect.

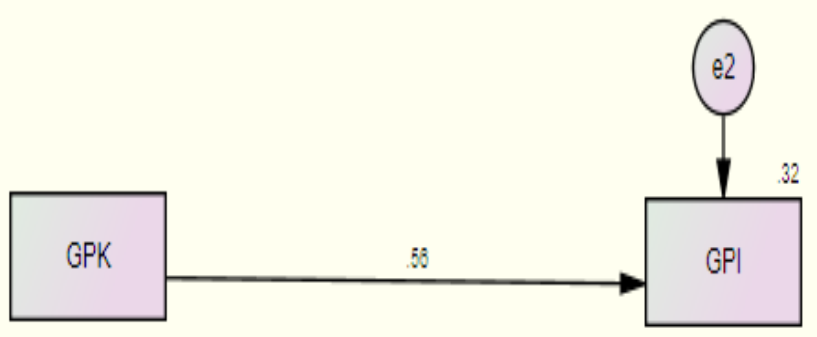

Figure 2 Path result without mediation

As shown in figure 2 the path coefficient is statistically significant at .56 or $56 \%$, indicating GPK is related with GPI in a positive manner. Also this can be seen from table 5 and table 6 , table 5 shows that the $\mathrm{P}>.05$.

Table 5 Path Coefficients

\begin{tabular}{|l|l|l|l|l|}
\hline \multicolumn{2}{|l|}{} & \multicolumn{1}{l|}{ CR } & P \\
\hline GPI & $<----$ & GPK & 8.493 & 0 \\
\hline
\end{tabular}

Table 6 shows the beta value also called estimate .564 that can also be seen in figure 2. This is the first check to see if the effect is significant or not.

Table 6 Variance explained Beta Value

\begin{tabular}{|l|r|}
\hline & BetaValue \\
\hline GPI <--- GPK & .564 \\
\hline
\end{tabular}

The next check was to see the structural model with word of mouth acting as the mediator as shown below.

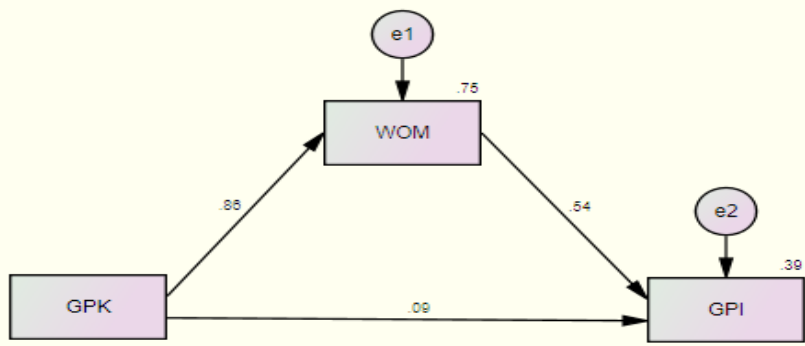

Figure 3 Path result with mediation

The details of figure 3 is most interesting as it is clearly showing that the moment we include word of mouth (WOM) as a mediator there is an effect on green purchase intention (GPI) and all effect is now through the mediator (WOM) and the path that was earlier significant .564 table 6 is no more significant .093 table 8 , this is a case of full mediation.

\section{Table 7 Details of path coefficients}

\begin{tabular}{|c|c|c|c|c|}
\hline & & & $\begin{array}{r}\text { Criti } \\
\text { cal } \\
\text { Ratio } \\
\end{array}$ & $\begin{array}{r}\text { Probabil } \\
\text { ity }\end{array}$ \\
\hline WOM & $<$ & GPK & 21.356 & **** \\
\hline GPI & $<$ & WOM & 4.385 & **** \\
\hline GPI & $<$ & GPK & 0.747 & 0.455 \\
\hline
\end{tabular}

Table 7 is displaying C.R. value for path GPK->WOM it is 21.356 which is quite huge as C.R. in AMOS is t value and the cut-off of $t$ value is 1.95 , meaning that any value that is above 1.95 is statistically significant as its $P$ value will be above 0.05 as shown in this table. The path between WOM and GPI has $t$ value of 4.385 , this is also above 1.95 . and finally path coefficients between GPK and GPI has now become insignificant as its $t$ value has dropped from 8.493 table 5 to 0.747 table 7 , showing there is a powerful mediation going on.

\section{Table \& R² Details}

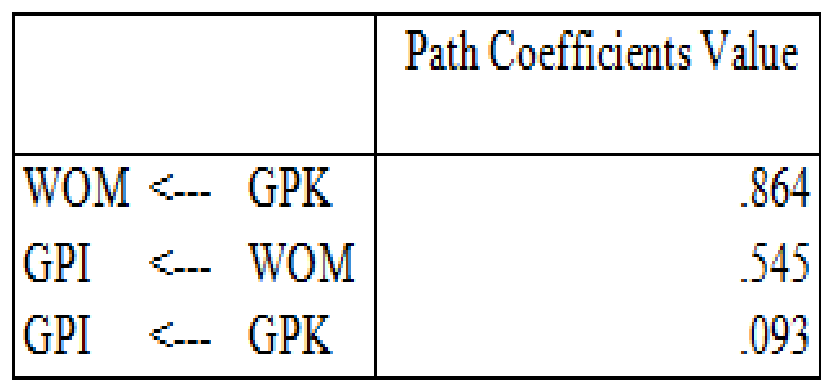

Finally it was time to test our three hypothesis as shown in table 9 


\section{Understanding the Mediating Effect of Word of Mouth on Green Products Purchase Intention}

Table 9 Hypothesis testing

\begin{tabular}{|l|c|c|}
\hline Hypothesis & $\begin{array}{c}\text { T Statistics } \\
\text { (|O/STERR |) }\end{array}$ & $\begin{array}{c}\text { Hypothesis } \\
\text { Result }\end{array}$ \\
\hline GPK -> GPI & 0.747 & Not Supported \\
\hline GPK -> WOM & 4.385 & Supported \\
\hline WOM -> GPI & 21.356 & Supported \\
\hline
\end{tabular}

Our first hypothesis was rejected and second and third hypothesis was accepted as $\mathrm{t}$ - value must be above 1.95 .

\section{CONCLUSION}

Now Environment is degrading at a fast pace. It is better now to ponder over it and stop degradation of environment rather regret it at a later date. Apart from other measures of saving environment by preventing wastage of water and electricity and also recycling of products, usage of green products through Green Marketing are some of the factors for preventing the degeneration of Environment. Word of Mouth publicity is important for overall success of green products. Though, people understand Green Products are better, but they can use on recommendation and also on economic considerations.

The marketers and customers both need eco - friendly environment, as after all they all live in one society. So if marketer looks for sustenance in this competition, they have to move towards the Eco -friendly concept. Green marketing has become indispensable to save this planet. Green Marketing cannot ignore monetary aspect. It's not the only responsibility of marketers to protect environment, it also requires the readiness of the consumer to choose Eco-friendly products for ensuring that price is not a constraint for them. It was also seen that green washing can have a negative impact WOM and this can create a barrier for the success of green products.

\section{REFERENCES}

1. Bhatia, M., \& Jain, A. (2013). Green marketing: A study of consumer perception and preferences in India. Electronic Green Journal, 1(36), 1-19.

2. Boztepe, A. (2012). Green marketing and its impact on consumer buying behavior. European Journal of Economic and Political Studies, $5(1), 5-21$

3. Chamorro, A., Rubio, S., \& Miranda, F. J. (2009). Characteristics of research on green marketing. Business Strategy and the Environment, 18(4), 223-239.

4. Chen, T. B., \& Chai, L. T. (2010). Attitude towards the environment and green products: consumers' perspective. Management Science and Engineering, 4(2), 27-39.

5. Cherian, J., \& Jacob, J. (2012). Green marketing: A study of consumers' attitude towards environment friendly products. Asían Social Science, $8(12), 117-126$

6. D'Souza, C. (2004). Ecolabel programmes: A stakeholder (consumer) perspective. Corporate Communications: An International Journal, 9(3), 179-188.

7. D’Souza, C., Taghian, M., \& Lamb, P. (2006). An empirical study on the influence of environmental labels on consumers. Corporate Communications: An International Journal, 11(2), 162-173.

8. Grunert, S. C. (1993). Everybody seems concerned about the environment: But is this concern reflected in Danish consumers' food choice? In W. F. V. Raaij, \& G. J. Bamossy (Eds.), European advances in consumer research (pp. 428-433). Provo, UT: Association for Consumer Research

9. Kiran, K. U. (2012). Opportunity and challenges of green marketing with special references to Pune. International Journal of Management and Social Sciences Research, 1(1), 2319-4421.
10. Kumar, P. (2015). Green marketing products in India. DAV Academic Review, 1(1), 1-12.

11. Lee, K. (2008). Opportunities for green marketing: Young consumers Marketing Intelligence and Planning, 26(6), 573-586.

12. Lee, K. (2009). Gender differences in Hong Kong adolescent consumers' green purchasing behavior. Journal of Consumer Marketing, 26(2), 87-96.

13. Maheshwari, A., \& Malhotra, G. (2011). Green marketing: A study on Indian youth. International Journal of Management and Strategy, 2(3), $1-15$.

14. Manaktola, K., \& Jauhari, V. (2007). Exploring consumer attitude and behaviour towards green practices in the lodging industry in India. International Journal of Contemporary Hospitality Management, 19(5), 364-377.

15. Manian, K., \& Ashwin, J. N. (2014). Present green marketing-brief reference to Indian scenario. International Journal of Scientific Research and Management, 2(3), 51-57.

16. Rahbar, E., \& Abdul Wahid, N. (2011). Investigation of green marketing tools' effect on consumers' purchase behavior. Business Strategy Series, 12(2), 73-83.

17. Yazdanifard, R., \& Mercy, I. E. (2011). The impact of green marketing on customer satisfaction and environmental safety. Proceedings of International Conference on Computer Communication and Management (pp. 637-641).

18. Singapore: IACSIT Press. Retrieved from https:// pdfs.semanticscholar.org/cb39/27334b3e89761d 573 caaf $47 \mathrm{cff} 55 \mathrm{c} 22 \mathrm{ec} 2 \mathrm{~d} 6 . \mathrm{pdf}$

\section{AUTHORS PROFILE}

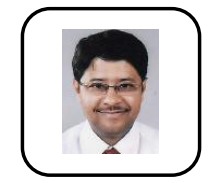

Mr. Mayank Pant, is a Research Scholar in Uttaranchal University, he has to his credit 12 research papers out of which one is in SAGE publication, he is well quipped with statistical softwares like IBM SPSS, AMOS, ADANCO R Studio, SMART PLS. He is certified AFRM from IIM Kashipur and also possess DOEACC "O” Level certification.

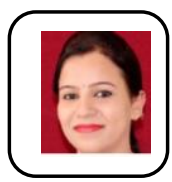

Ms. Anu Sayal, is currently working as Assistant Professor in Mathematics in Uttaranchal Institute of Management, Uttaranchal University, Dehradun. She has done her schooling from Convent of Jesus and Mary, Dehradun. She has done Bachelors in non medical from Guru Nanak Dev University, Amritsar. Her Post Graduation was in Mathematics from Guru Nanak Dev University, Amritsar. She was the college topper in Mathematics in Graduation. Presently she is also pursuing $\mathrm{PhD}$ in Mathematics from UTU Dehradun.

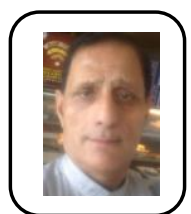

Mr V K Tangri is currently working as Assistan Professor in Uttarancal University in Uttaranchal Institute of Management, he is an eminent eacher in the field of Law and Finance, he has a vast experience in Banking and teaching profession.

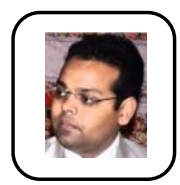

Dr Mohammad Tariq Intezar is an Associate Professor in University of Petroleum and Energy Studies Dehradun An experienced Management Faculty over more than a decade teaching and research. He is Master in Commerce, MBA in Marketing and Ph.D. from AMU, Aligarh, India. Recently he completed Faculty Development Program in Management (FDPM) from India's top leading Business School Indian Institute of Management Ahmedabad (IIMA) in 2016 and holds life membership of this prestigious institute. 